\title{
Management of Undescended Testes: A Retrospective Study from a Tertiary Hospital in Ethiopia
}

\author{
M Gama ${ }^{1}$, A Tadesse ${ }^{2}$, B Dejene ${ }^{2}$, H Getachew ${ }^{2}$, T Nigussie², M Derbew ${ }^{2}$ \\ ${ }^{1}$ Department of Surgery, St. Paul's Hospital, Millennium Medical College, Addis \\ Ababa, Ethiopia \\ ${ }^{2}$ Department of Surgery, School of Medicine, Addis Ababa University, Addis \\ Ababa, Ethiopia
}

Correspondence to: Miliard Derbewmilliardderbew@gmail.com, https://dx.doi.org/10.4314/ecajs.v22i1.10

Background: Undescended testis is one of the commonest congenital malformations seen in boys. The aim of this study is to evaluate the pattern of presentation, approach to diagnosis, treatment and follow up in Tikur Anbesa Specialized Hospital, a tertiary teaching hospital in Ethiopia.

Methods- This is a retrospective cross sectional study of all boys with undescended testis operated in Tikur Anbesa Specialized Hospital between September 2012 and August 2014.

Results: Of 82 boys operated within the study period, 66 boys with 78 undescended testes are studied. Twenty-six percent (17/66)came before the age of 2 years, while the majority of the study group, 50\% (33/66), presented beyond 5 years of age. Of the 17 boys brought to the hospital before 2 years, only $41 \%(7 / 17)$ them were treated before the age of two years. The majority 89\% (59/66) of the boys were treated after 2 years of age. Seventy-one testes of 78 [91\%] were in the inguinal canal, 5 were intra-abdominal and 2 were absent. $46 \%$ (36/78) were on the left side, $29 \%$ (23/78) on the right side and the rest were bilateral. Among the 54 boys who had ultrasound examination, the ultrasound report is consistent with operative findings in 33 [61\%]. Associated congenital malformations were found in $31.8 \%(21 / 66)$ of the boys. Hypospadia was the predominant malformation comprising $38 \%$ (8/21) of the total congenital malformations. Orchidopexy was done for $82 \%(64 / 78)$ of the total testes, orchiectomy was done for $9 \%(7 / 78)$ and biopsy was taken in 1 case. Among the total operated boys only 62\% (41/66) were followed in our clinic; of those who had follow up 10\% (4/41) testes atrophied and 1 [2\%] testis retracted.

Conclusion: Boys with undescended testes present and are treated late in Tikur Anbesa Hospital. As opposed to the literatures most of the undescended testes were found on the left side. Ultrasound examination cannot be the only mode of examination for undescended testes as it misses more than one third of the cases. Hypospadia is the commonest associated congenital malformation. Post operative follow up is very poor after treatment for undescended testes

\section{Introduction}

Undescended testes (UDT) is a common congenital malformation in boys ${ }^{1}$. The prevalence of undescended testes in term infants, according to European literature, is 1 to $3 \%^{2}$. A study out of Nigeria estimates the prevalence in Africa to be 0.8 to $2 \%$ among term infants ${ }^{3,4}$. The 


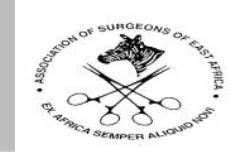

prevalence is higher in premature boys 15 to $30 \%$, and drops to $1 \%$ at one year of age. Unless treated, descent after this time is not expected.

Undescended testes develop progressive histological changes during the first few years of life, such as defective transformation of gametocyte and loss of germ cell. These changes are apparent from two years of age onwards. Loss of seminiferous tissue may cause atrophy of the testes. The histological changes observed in cryptorchidism are most likely due to temperature-related damage and low fertility. The testis may undergo torsion or sustain trauma, and the risk of malignancy in undescended testis is relatively high.

As in any clinical evaluation of all other patients, boys with undescended testes deserve proper history taking and physical examination. History and physical examination is indispensable in early detection and management of this problem. The current diagnostic standard is laparoscopy; it is also valuable for treatment of undescended testis ${ }^{5}$.

Successful scrotal repositioning of the testis may reduce, but does not prevent, the potential long-term issues of infertility and testicular cancer, and appropriate counseling and followup of the patient are essential 6 . According to a study of 51 formerly cryptorchid subjects who had undergone surgery in the first 2 years of life, sperm count and motility were normal in more than $95 \%$ at $18-26$ years of age, with even better fertility prognosis if Orchidopexy was performed during the first year of life $(96.3 \%$ for both normal sperm count and sperm motility) ${ }^{7}$.

\section{Patients and Methods.}

This is a retrospective cross sectional study conducted in Tikur Anbesa Specialized Hospital (TASH). The study included all boys with undescended testes operated between September 2012 and August 2014. Operation log book was used as the initial source of patient information. Registration numbers of operated boys were collected from the operation log book, and then corresponding charts were collected from the chart room. The history, physical examination, ultrasound findings, operation note and the follow up notes were documented from individual files.

\section{Results}

During the study period, 82 boys underwent operations for undescended testes. Of these cases, 66 charts were retrieved. These 66 boys with a total of 78 undescended testes were included in the study. The median age at presentation was 60 months [range: 2 months to 156 months]. Seventeen boys (25.8\%) presented from birth to 23 months of age, $24.2 \%$ (16/66) presented between 24 months to 59 months of age, $28.8 \%(19 / 66)$ presented between 60 months to 119 months and 21.2\% (14/66) presented at 120 months and above. (Table 1).

Of the 66 boys brought for medical attention, 17 (26\%) came before the age of two years, 7 $(10.6 \%)$ were treated before age 2 . Ten (15\%) who came before the age of two years didn't get the surgical treatment in time. Nineteen boys $(28.8 \%)$ were treated between the age of 


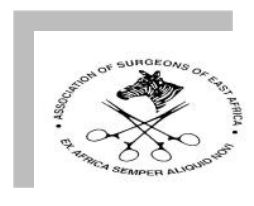

24 to 59 months, 24 [36.4\%] underwent operations between the ages of 60 and 119 months, and 16 [24.2\%] were treated after the age of 120 months (Table 2). Eighty-two percent $(54 / 66)$ cases were unilateral while $18 \%(12 / 66)$ were bilateral. Left sided undescended testes was found in $55 \%(36 / 66)$, while $27 \%(12 / 66)$ were on right side and 12 18\% (12/66) were bilateral (Table 3).

Table 1. Age at Presentation in Months

\begin{tabular}{|c|c|c|}
\hline Age in month & Frequency & Percent \\
\hline$<24$ & 17 & 25.8 \\
\hline 24 to59 & 16 & 24.2 \\
\hline 60 to 119 & 19 & 28.8 \\
\hline$>120$ & 14 & 21.2 \\
\hline Total & 66 & 100 \\
\hline
\end{tabular}

Table 2. Age at Presentation and Age at Treatment Categorized

\begin{tabular}{|c|c|c|c|c|c|c|}
\hline & & \multicolumn{4}{|c|}{ Age in Months at treatment categorized } & \multirow[t]{2}{*}{ Total } \\
\hline & & $<24$ & $24-59$ & $60-119$ & $120+$ & \\
\hline Age in Months & $<24$ & 7 & 3 & 5 & 2 & 17 \\
\hline \multirow[t]{3}{*}{ at presentation } & $24-59$ & 0 & 13 & 3 & 0 & 16 \\
\hline & $60-119$ & 0 & 3 & 14 & 2 & 19 \\
\hline & $120+$ & 0 & 0 & 2 & 12 & 14 \\
\hline \multicolumn{2}{|l|}{ Total } & 7 & 19 & 24 & 16 & 66 \\
\hline
\end{tabular}

Table 3. Affected side

\begin{tabular}{|l|c|c|}
\hline Unilateral/Bilateral & Frequency & Percent \\
\hline Bilateral & 12 & 18 \\
\hline Unilateral & 54 & 82 \\
\hline Total & 66 & 100 \\
\hline
\end{tabular}




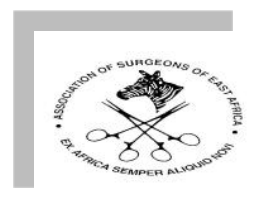

Ninety-one percent (71/78) testes were found in the inguinal canal, $6 \%(5 / 78)$ were found intra-abdominal, $3 \%(2 / 78)$ were not found after exploration of inguinal canal and abdominal cavity [absent testis]. See table 4

Fifty-four boys of the 66 underwent ultrasound. The operative finding and ultrasound report were consistent in 33 [61\%] of boys, and the report was different from operative findings in 21 [39\%]. Twelve cases have no ultrasound report. No proper description of physical finding of the scrotal status or the status of the testes is mentioned in any of the cases

Associated congenital malformations were found in 32\% (21/66) of the boys. Hypospadia was found in 9 (43\%), Hirschsprung's disease (HSD) accounted for $10 \%(2 / 21)$ of congenital abnormalities, renal abnormalities [ectopic kidney, hydronephrosis] were in 2 [10\%] and others (Table 5).

Table 4. Site of Testes

\begin{tabular}{lc} 
Site & Number \\
\hline In the inguinal canal & 71 \\
\hline Intra abdominal & 5 \\
\hline Not found [Absent testes] & 2
\end{tabular}

Table 5: Associated Anomalies

\begin{tabular}{|c|c|c|}
\hline \multicolumn{2}{|c|}{ Congenital malformation } & Number of boys \\
\hline \multicolumn{2}{|c|}{ Hypospadia } & 9 \\
\hline \multicolumn{2}{|l|}{ HSD } & 2 \\
\hline \multirow[t]{2}{*}{ CNS } & Cerebral palsy & 1 \\
\hline & Seizure disorder & 2 \\
\hline \multirow[t]{2}{*}{ Kidney } & Ectopic & 1 \\
\hline & Hydronephrosis & 1 \\
\hline \multicolumn{2}{|c|}{ Hydrocele } & 2 \\
\hline \multicolumn{2}{|c|}{ Umbilical hernia } & 2 \\
\hline \multicolumn{2}{|l|}{ ARM } & 1 \\
\hline \multicolumn{2}{|c|}{ Micropenis } & 2 \\
\hline \multicolumn{2}{|c|}{ Cataract [bilateral] } & 1 \\
\hline
\end{tabular}


Table 6: Management Outcome

Management out come

Not known [disappeared from follow up]

Normal

Atrophied

Recurrent Undescended testis

\section{Number}

25

36

4

1

\section{Percent}

$38 \%$

$88 \%$

$10 \%$

$2 \%$

Orchidopexy was performed for $82 \%$ (64/78) of undescended testes; $9 \%$ (7/78) underwent orchiectomy, 4 testes [5\%] are fixed somewhere in the inguinal canal and a biopsy of 1 testes [1\%] was taken. Two testes were not found on exploration. Post-operative follow up was conducted for a minimum of 3 months. Twenty-five boys [38\%] were lost to follow up, 41 boys [62\%] had follow-up for more than 3 months. Among boys who had post operative follow up, four [10\%] boys had atrophied testes and one [1\%] had recurrent undescended testis (Table 6).

\section{Discussion}

In accordance with the recommendation of diagnosis and treatment of UDT only 17 boys [26\%] presented for medical attention before the age of 2 years. Of these only $10.6 \%$ got treatment before the age of 2 . The vast majority of children, 49 of 66 boys $74 \%$ presented after 2 years of age. Fourteen boys $21 \%$ were older than 10 years at the time of presentation. This could be an indicator for lack of awareness of the parents either about the presence of the pathology or lack of knowledge of the treatability of the problem, lack of access to health facility, poverty or a combination of reasons. Birth attendants, who are conducting the delivery, might not have awareness of the need to examine the gross abnormality such as undescended testis to detect the problem at an earlier age, so that further follow up can be made.

A Similar study conducted in Nigeria, Lagos shows $25 \%$ of the boys were treated before the age of 2 years ${ }^{1}$; another study conducted in Nnwi [South East Nigeria] on 71 boys with 86 UDT revealed $33.3 \%$ of boys with undescended testes were treated before the age of 2 years ${ }^{2}$. At the University of Benin [Benin City], 43.7\% boys were treated at the age of 5 years and below ${ }^{3}$. At Medical College Hospital, Alappuzha, Kerala, India, and n Zaria, Nigeria, the percentage of patients who underwent Orchidopexy before the age of 2 years is $19.4 \%$ and $11 \%$ respectively ${ }^{8,9}$. That $10.6 \%$ of our patients presented after 2 years of age shows a similar trend to other low resource setting.Of those 17 (26\%) boys brought to our hospital, only $7(10.6 \%)$ boys got treatment before the age of 2 years. This is also an indicator of significant delay of treatment even after the children were seen in our hospital. Therefore, the problem of early management is seen at all levels. 
Ultrasound study was performed for preoperative evaluation of 54 boys. For 12 cases preoperative evaluation of ultrasound was performed. Of the 54 ultrasounds conducted, the preoperative finding is consistent with the intra- operative finding in 33 cases (61\%). The sensitivity in this study is $61 \%$. A study out of the University of California, San Francisco showed a sensitivity and specificity of $45 \%$ and $78 \%$, respectively. In a study out of the Benin University teaching Hospital in 2008, ultrasound was used to localize only 10 [11.6\%] of the testis ${ }^{3}$. In Zaria, Nigeria, Ultrasonography was performed for three non-palpable testes but was not helpful (9). Our data adds to this literature which suggests that ultrasound may not be a reliable investigative tool for non-palpable testes as it is unable to efficiently rule-out intra-abdominal testes.

Previous work suggests that laparoscopic Orchidopexy presents excellent results in terms of diagnosis and therapy of the impalpable testis ${ }^{5}$, our department should strive to use of laparoscopy for the management of impalpable testis. In our study, of the 66 boys with undescended testes 12 [18\%] were bilateral, 18 [27\%] were on the Rt. Side and 36 [55\%] were on the Lt. Side. The usual teaching that UDT is common on the right side is not seen in this study. But this finding is in line with the study conducted in University of Benin which showed $47.9 \%$ left side, $31.0 \%$ on the right side and $21.1 \%$ bilateral 3 . The reason for the predominance on the left side seen in this study and others needs further investigation. The occurrence of bilateral undescended testis is apparently less common when compared with the other studies.

Congenital malformation was found in 32\% of the study population [ 21 of the 66 boys]. Hypospadia is the most common associated congenital malformation. It accounts for $38 \%$ of congenital malformations and it is found in $14 \%$ of the study group. Renal, central nervous system and intestine are the common organs where malformations are detected in this study. From this study it is realized that boys presented with undescended testes should be investigated for associated congenital malformations. A study done in Lagos University teaching Hospital where 56 boys with undescended testes were examined revealed 6 [10.7\%] of congenital malformation of which 5 [83.3\% of the congenital abnormalities] were hypospadias ${ }^{11}$. The combination of Hypospadia and undescended testicle sometimes indicates a disorder of sexual differentiation, and additional investigation like karyotyping and hormonal assays are recommended to investigate the malformations. Therefore, while we are planning to manage undescended tastes, we need to investigate for any associated congenital anomaly.

Of the 78 UDT 91\% testes were detected in the respective inguinal canal, $6 \%$ were intraabdominal, $3 \%$ was not found on exploration, $9 \%$ testes were atrophied on first evaluation. Orchidopexy was done for 64 testes, orchiectomy was done for seven testes; four of the UDT were fixed somewhere in the inguinal canal. A study from Tanzania revealed $70 \%$ of UDT were inguinal and $30 \%$ cases are abdominal and $26.7 \%$ were atrophied ${ }^{12}$.

It is difficult to draw conclusions about the management outcome from this study as many of our patients were lost to follow up. Twenty-five (38\%) of the study group was lost to follow up. In our setting, there are many reasons for high levels of loss to follow up. Parents 
may not be given enough information about the need for proper follow up, problem of distance [accessibility], and others. From the 41 boys on follow up 4 [10\%] testes were atrophied, and there was one case of recurrence. The 4 atrophied testes were in those boys treated beyond the age of 5 years and one child with recurrence was treated before the age of 5 years. Similar study conducted in Dar-es-Salaam reported that $29.8 \%$ of post operative patients had atrophied testicles ${ }^{13}$. At the University of Benin, 10 boys [14.1\%] were found to have atretic testicles and all were detected in boys treated above the age of 5 years. It was found out that $11.1 \%$ of total testes were atrophic/vanished in the review from Kerala ${ }^{8}$.Our atrophy rate is also similar with the reports from centers in other developing countries.

\section{Limitations}

The major limitation in this study was lack of proper patient record keeping. In this study, it is seen that number of patients operated within the study period was 82 , but only 66 cards were found. The other 12 [15\%] cards are missing, which and not only affects research activities, but also patient management. This indicates that the recoding keeping needs improvement.

\section{Conclusions}

Patients with undescended testes often present late, which is detrimental to good outcomes. As it is seen in this study, ultrasound is not a reliable diagnostic instrument, when used in isolation, as it misses more than one third of patients.

Evaluation of associated congenital malformation is important. Hypospadias is one of the most common malformations seen. More than one third of the operated boys did not appear for follow up. In this case it is difficult to evaluate the management out come and to set the plan of action.

\section{Recommendations}

- The vast majority of boys present for treatment after histological change has occurred. In fact, this is an alarming finding to make us start to educate and create awareness of both parents, midwifes and other birth attendants so that early detection and referral should be made

- In addition to awareness creation of the parents and the birth attendants improving the health service delivery capacity of the existing hospitals and to start this service in the others hospitals should be done.

- It is time to start electronic patient record keeping like the other part of the the world. And this will not only solve all the complaints related to patients file and management but also facilitate and makes simple research activities.

\section{Acknowledgement}

We are grateful to Dr Assefa Sime from the School of Public health for his invaluable contribution. 
References

1. O.A. Adesanya1, A.O. Ademuyiwa2, O.A. Elebute2, R. Ojewola3, C.O. Bode2The Undescended Testes in Children: a Prospective Epidemiological Study Lagos University Teaching Hospital, Lagos

[ISSN 2073_ 9990 East Cent. Afr.J.surj, COSECSA/ASEA Publication_East and Central African Journal of Surgery. July/Augest:2013

2. Osuigwe AN, Nwose PC, Ndukwu C, Dilibe UC. Undescended Testis at NnamdiAzikiweTeaching Hospital, Nnewi, Nigeria - A Ten Year Audit. African Journal of Urology 2005;11(2): 101-104.

3. OsifoOsarumwense David, Evbuomwanlyekoreti_ Undescendedtestesin a developing country: A study of the management of 71 patients. Paed. Surgery Unit, Department of Surgery, University of Benin, Teaching Hospital, Benin City, Nigeria.[2008, issue:1]

4. Okeke AA, Osegbe DN. Prevalence and characteristics of cryptorchidism in a Nigerian district. BJU International. 2001: 88 (9) : 941-945

5. Denes FT, Saito FJ, Silva FA, Giron AM, Machado M, Srougi M. Laparoscopic diagnosis and treatment of nonpalpable testis. IntBraz J Urol. 2008;34(3):329-334

6. [Guideline] Kolon TF, Herndon A, Baker LA, et al. Evaluation and Treatment of Cryptorchidism: AUA Guideline. Journal of Urology. American Urological Association. Published online May 20, 2014. Available at http://www.jurology.com/article/S00225347(14)03531-9/fulltext. Accessed: November 12, 2014.

7. Feyles F, Peiretti V, Mussa A, Manenti M, Canavese F, Cortese MG, et al. Improved sperm count and motility in young men surgically treated for cryptorchidism in the first year of life. Eur J Pediatr Surg. 2014 Oct. 24(5):376-80. [Medline].

8. Rajendran R, Sathyanji EK, Pai R. Age of treatment of undescended testis: A study. J Indian Med Assoc. 2002; 100:6623.

9. Ameh EA, Mbibu HN. Management of undescended testes in children in Zaria, Nigeria. East Afr. Med J 2000; 77:485-487

10.Gregory E. Tasian MD, MSc, and Hillary L Copp, MD, MS. Diagnostic Performance of Ultrasound in Non palpable Cryptorchidism: A Systematic Review and Meta-analysis PEDIATRICS Volume 127, Number 1, January 2011, Department of urology, University of California, San Francisco

11.O.A. Adesanya1, A.O. Ademuyiwa2, O.A. Elebute2, R. Ojewola3, C.O. Bode2. The Undescended Testes in Children: a Prospective Epidemiological Study. Lagos University Teaching Hospital (LUTH

12.G, AfrikaGasana, K.A. Mteta. Pattern of presentation and management of patients with undescended testis at Kilimanjaro Christian Medical Center, Tanzania. African journal of urology _ volume16, issue3, September 2012, Page 124-126.

13. MlySM. SayiEN. Undescended testis in pediatric patients at Muhimbili Medical Center, Dar-es Salaam. East African Medical Journal 1994:71:135-7. 